University of Nebraska - Lincoln

DigitalCommons@University of Nebraska - Lincoln

USDA National Wildlife Research Center - Staff

Publications
U.S. Department of Agriculture: Animal and Plant Health Inspection Service

March 2006

\title{
Multiple breeding strategies in the swift fox, Vulpes velox
}

Ann M. Kitchen

Utah State University

Eric M. Gese

USDA/APHIS/WS National Wildlife Research Center, eric.gese@usu.edu

Lisette P. Waits

University of Idaho

Seija M. Karki

Utah State University

Edward R. Schauster

Utah State University

Follow this and additional works at: https://digitalcommons.unl.edu/icwdm_usdanwrc

Part of the Environmental Sciences Commons

Kitchen, Ann M.; Gese, Eric M.; Waits, Lisette P.; Karki, Seija M.; and Schauster, Edward R., "Multiple breeding strategies in the swift fox, Vulpes velox" (2006). USDA National Wildlife Research Center - Staff Publications. 110.

https://digitalcommons.unl.edu/icwdm_usdanwrc/110

This Article is brought to you for free and open access by the U.S. Department of Agriculture: Animal and Plant Health Inspection Service at DigitalCommons@University of Nebraska - Lincoln. It has been accepted for inclusion in USDA National Wildlife Research Center - Staff Publications by an authorized administrator of DigitalCommons@University of Nebraska - Lincoln. 


\title{
Multiple breeding strategies in the swift fox, Vulpes velox
}

\author{
ANN M. KITCHEN*, ERIC M. GESE†, LISETTE P. WAITS $\ddagger$ SEIJA M. KARKI* \& EDWARD R. SCHAUSTER* \\ ${ }^{*}$ Department of Forest, Range and Wildlife Sciences, Utah State University, Logan \\ $\dagger$ U.S. Department of Agriculture, Wildlife Services, National Wildlife Research Center, \\ Department of Forest, Range and Wildlife Sciences, Utah State University, Logan \\ $\ddagger$ Department of Fish and Wildlife Resources, University of Idaho, Moscow
}

(Received 12 November 2004; initial acceptance 25 March 2005;

final acceptance 16 June 2005; published online 13 March 2006; MS. number: A10041)

\begin{abstract}
Little is known of the mating system of the swift fox or how it compares to other socially monogamous mammals. In a 4-year study of 188 swift foxes, we used microsatellite analysis at 11 loci along with spatial observations to investigate swift fox mating strategies. The mating strategies used by swift foxes were highly diverse. Previous field observations have indicated that the swift fox is socially monogamous. However, we found that extrapair mating was a common breeding strategy; $52 \%$ of offspring were sired by a male that was not the mate of their mother. There was also variation in the structure of social groups. Of 59 social groups, the most common consisted of a male and female pair (93\% of social groups); however, four stable trios of both one female and two males (5\%) and two females and one male (2\%) were also evident. The trio groups were spatially associated, and at least one member of each trio was highly related to a member in at least one other trio. Swift foxes also engaged in mate switching, which refutes the prevailing hypothesis that they always mate for life. Thus, we found that the mating system of the swift fox is highly diverse and substantially more complex than previously believed. We discuss factors that may influence which strategies are adopted and whether they are adaptive.
\end{abstract}

2006 The Association for the Study of Animal Behaviour. Published by Elsevier Ltd.

Results from genetic studies of mating patterns have often differed markedly from results of previous, exclusively observational studies (Hughes 1998). There is increasing evidence that breeding systems may be substantially more complex and incorporate a greater variety of strategies than formerly documented. For example, a mixed strategy of maintaining a stable bond with one mate but engaging in extrapair matings with others is more common than previously thought in numerous taxa (Birkhead \& Møller 1993; Morell 1998; Griffith et al. 2002).

Much of the early evidence of the occurrence of extrapair paternity comes from studies on birds (Birkhead 1987; Westneat et al. 1990), but there is also evidence that extrapair paternity may occur in many socially monogamous mammals. For example, genetic data have shown extrapair paternity in the socially monogamous island fox, Urocyon littoralis (Roemer et al. 2001), the hooded seal, Cystophora cristata (McRae \& Kovacs 1994) and the Alpine marmot, Marmota marmota (Goossens et al.

Correspondence: A. M. (Kitchen) Henderson, Monitoring and Assessment of Biodiversity Program, Smithsonian Institution, NZP-CRC MRC 705, P.O. Box 37012, Washington, D.C. 20013-7012, U.S.A. (email: hendersonan@si.edu).
1998). In the Ethiopian wolf, Canis simensis, 70\% of observed copulations were between a female of one pack and a male from the adjoining pack (Sillero-Zubiri 1994). This evidence may not imply high levels of extrapair paternity, however, because studies of birds have shown little correlation between the frequency of extrapair copulations and extrapair paternity (Westneat 1987a, b).

The structure and stability of breeding groups may also be more variable than previously thought, and studies incorporating observational and genetic information are needed to fully describe breeding group structure and function. Many factors can influence breeding group structure. These include physiological and sociological factors, such as body size, sexual dimorphism and parental care (Alexander 1974; Moehlman 1986), and environmental factors, such as prey abundance and population density (Macdonald 1983; Geffen et al. 1996). Moehlman (1986) argued that group structure was correlated with body size among canid species.

The pervasive mating system in canids is monogamy (Kleiman 1977); however, many small canids have occasional polygyny (e.g. red foxes, Vulpes vulpes: Macdonald 1979; bat-eared foxes, Otocyon megalotis: Pauw 2000). Evidence indicates that swift foxes ( $V$. velox) also follow this pattern, generally living in socially monogamous pairs, 
with the occasional trio of two females and one male (Egoscue 1979; Kamler 2002). In contrast, many of the larger canids (e.g. African hunting dogs, Lycaon pictus: van Lawick 1973; Ethiopian wolves: Sillero-Zubiri 1994) show occasional polyandry.

Other species deviate from the trend based on body size (e.g. Blanford foxes, V. cana: Geffen \& Macdonald 1992; maned wolf, Chrysocyon brachyurus: Dietz 1984; Arctic fox, Alopex lagopus: Frafjord 1993). Geffen \& Macdonald (1992) hypothesized that, although body size may have an association with mating patterns, it is an indirect association. Body size may determine foraging tendencies and other ecological attributes, and thus factors such as resource distribution will be more influential in dictating social organization. Group size may also be influenced by limited breeding opportunities, with nonbreeding individuals remaining in social groups in the event that they cannot find breeding opportunities elsewhere.

The swift fox is one of the smallest of the North American canids. Weights of either sex range from 1.6 to $3.0 \mathrm{~kg}$, with males slightly heavier (average $=2.0-2.4 \mathrm{~kg}$ ) than females (average $=1.9-2.2 \mathrm{~kg}$; Sheldon 1992). The fox inhabits short and medium grass prairies and open plains. They are opportunistic feeders, with a diet including insects, cottontail rabbits, black-tailed jackrabbits, rodents, birds, lizards and vegetation (Zumbaugh et al. 1985; Kitchen et al. 1999). Members of social groups form long-term bonds; groups hold shared home ranges year-round and most commonly remain together until the death of one group member (Kilgore 1969; Cypher 2003). Denning areas are exclusive from neighbouring social groups (Schauster et al. 2002b). The extent of male parental care is unknown; however, Pruss (1994) noted some male involvement. An accurate description of the mating patterns of the swift fox is valuable to understanding mating systems in socially monogamous mammals in general. However, there is little research on the mating system of the swift fox, and all evidence comes from observational studies (e.g. Egoscue 1979; Kamler 2002).

We integrated genetic analyses with observational data to examine the reproductive strategies used by the swift fox. We discuss the social and ecological factors that may have shaped the strategies and whether they are adaptive. Our results allowed us to evaluate whether previous observational studies fully described swift fox mating patterns. We examined (1) whether swift foxes are fully (i.e. genetically as well as socially) monogamous as previously assumed or show extrapair paternity, (2) the prevalence of various group structures and (3) whether groups always remain stable until the death of one member, or whether group members instead engage in mate switching while their mate is still alive.

\section{METHODS}

The $1040-\mathrm{km}^{2}$ study area (Piñon Canyon Maneuver Site, PCMS, $37.52^{\circ} \mathrm{N}, 104.22^{\circ} \mathrm{W}$ ) is in Las Animas County, northeast of Trinidad, Colorado, U.S.A. The climate is semi-arid (range of mean annual precipitation ranging $26-38 \mathrm{~cm})$. Mean monthly temperatures range from
$-1{ }^{\circ} \mathrm{C}$ in January to $23^{\circ} \mathrm{C}$ in July. Elevations range from 1310 to $1740 \mathrm{~m}$, and the main vegetation type is shortgrass prairie (Shaw et al. 1989). The study area was used primarily for cattle ranching before 1982, when the U.S. Army acquired PCMS for military activities involving month-long, mechanized training sessions three to four times a year. Military training was generally in areas other than that used by the collared foxes and had little or no effect on the foxes.

Continuous data collection began in January 1997 and ended in December 2000. To obtain genetic samples on swift foxes and to examine their social groupings and mate choices, foxes were captured and radiocollared (collars weighed $46 \mathrm{~g}$ ). Foxes were captured opportunistically, so we were often unable to collar all members of family groups. Foxes were captured using double-door box traps $(80 \times 25 \times 25 \mathrm{~cm})$ baited with chicken (Covell 1992). Traps were deployed in the evening and checked the following morning. Trapping ceased during periods when nighttime temperatures dropped below $-10^{\circ} \mathrm{C}$. A radiocollar and eartag were attached to the fox, and the weight, sex and age (determined by tooth wear) of the animal were recorded. Ages of collared foxes that were later found dead were further assessed by dental cementum analysis, which involves counting the incremental growth layer on the teeth (Linhart \& Knowlton 1967). To recapture certain individuals to replace radiocollars, a trap-enclosure system (Covell 1992) was used. This involved surrounding an occupied den with chicken wire with exits into box traps. All foxes were released at the site of capture. The large size of PCMS allowed for the capture of foxes at five sites with varying seasonal population densities (range 0.14-0.33 foxes $/ \mathrm{km}^{2}$ per site, averaged over 1997 and 1998: Schauster et al. 2002a; Fig. 1). Fox densities were calculated as the total number of foxes at a site divided by the total area of actual or potential use of the site. The area of actual and potential use incorporated the total area of home ranges (100\% adaptive kernel estimator: Worton 1989) of the foxes buffered by the average radius of fox ranges for that site (Schauster et al. 2002a, b).

Radiocollared foxes were monitored to determine social groupings and mate choice. Telemetry procedures followed recommendations by White \& Garrott (1990). Locations were obtained by triangulating two to three bearings of the animals' position within $10 \mathrm{~min}$. Triangulation angles were maintained between $20^{\circ}$ and $160^{\circ}$ (Gese et al.

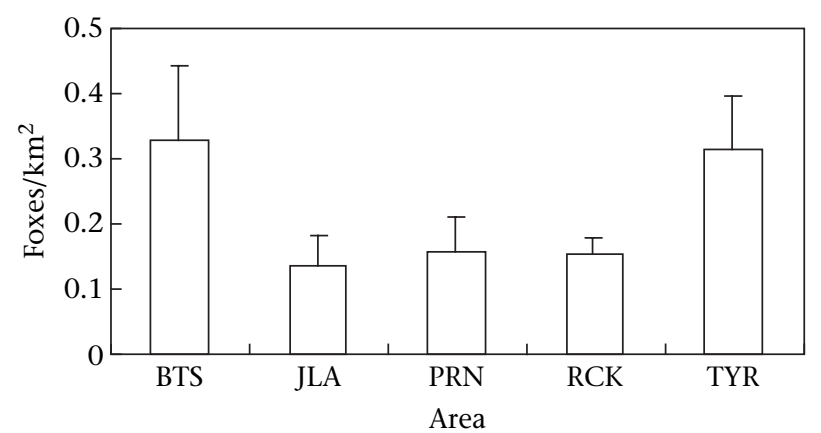

Figure 1. Seasonal density of swift foxes across five areas of the study site, Piñon Canyon Maneuver Site, Colorado, 1997-2000. 
1988). Aerial telemetry (Mech 1983) was used to locate missing animals. A relocation on each fox was attempted every 1-3 days, with locations obtained throughout the 24-h period to reduce bias in home-range estimates and associations between animals. When foxes were located in a den, the den location was recorded and marked. A social group was defined as foxes that shared a range and concurrently shared dens (Kitchen et al. 1999). Members of social groups are referred to as 'partners' or 'paired foxes' to distinguish them from breeding pairs (which may be within the social group or not). Movement patterns and range space use were assessed using Arcview 3.0 (Environmental Systems Research Institute, Inc., Redlands, California, U.S.A.). Home-range estimates were obtained only on foxes for which more than 30 locations per season were obtained.

Genetic relatedness between individual swift foxes within the population on the PCMS was assessed using 11 microsatellite markers. Blood samples were obtained from foxes caught in box traps and were frozen or stored in lysis buffer (Longmire et al. 1991) at a 1:5 ratio of blood to buffer. Tissue samples were taken from radiocollared animals found dead and were frozen until analysis. Fresh scat samples were collected during trapping, allowing for positive identification between the scat and the fox. Collected scats were frozen.

DNA was extracted from blood and tissue samples using a blood or tissue QIAGEN protocol (QIAGEN Inc., Valencia, California, U.S.A.) or a phenol/chloroform protocol (Vardenplas et al. 1984). DNA was extracted from scat samples in a room dedicated to processing low-quantity samples, using standard protocols of a QIAGEN stool kit and multiple negative controls to test for contamination. Samples were amplified through a polymerase chain reaction (PCR) with microsatellite primers (Saiki et al. 1985). PCR products were first run on a $1.5 \%$ agarose gel to test the quality of DNA extractions, and if necessary (i.e. when no band of the appropriate size appeared on the gel), a second extraction of the alternate type was performed. When PCR amplification was faint or absent after the second extraction, DNA extracts were concentrated and purified to remove inhibitors using standard
Geneclean protocols (Qbiogene, Inc., Carlsbad, California, U.S.A.).

Microsatellite primers developed for the dog genome and used for the closely related kit fox (Ostrander et al. 1993; Fredholm \& Wintero 1995; Francisco et al. 1996; Ralls et al. 2001) were optimized for the swift fox samples (Table 1). The following primers were used successfully: CXX20, CXX30, CXX173, CXX263, CXX403, CXX250, CXX109, CXX2062, CXX377, FH2054 and CPH3. Other primers that were tested but not used were CXX123, CXX225 and CXX2001 (rejected because of unsatisfactory amplification), and CXX172, CXX200 and FH2140 (rejected because of an insufficient number of alleles). For blood and tissue samples, the $20-\mu 1$ PCR reactions were cycled 35 times, with denaturation at $94^{\circ} \mathrm{C}$ for $30 \mathrm{~s}$ and annealing at 51 or $55^{\circ} \mathrm{C}$, depending on the primer pair (Table 1), for $30 \mathrm{~s}$, and extension at $72^{\circ} \mathrm{C}$ for $30 \mathrm{~s}$. Each primer was labelled with a fluorochrome (FAM, HEX or TET). Multiplexes of primers were developed to allow multiple loci to be run simultaneously. CXX20/CPH3, CXX109/CXX30, CXX403/CXX173 and CXX2062/ CXX250 were run as multiplexes, and CXX263, CXX377 and FH2054 were run as singleplexes. The concentrations of reagents that did not vary between reactions were dNTPs $(0.25 \mathrm{mM})$, BSA $(1.01 \mathrm{mg} / \mathrm{ml})$, Regular Taq buffer (1x) and Regular Taq (0.5 units). Reagents that varied were the primer concentrations and $\mathrm{MgCl}_{2}$ (Table 1 ). For scat samples, the PCR reactions were cycled 55 times, and 0.2 units of Gold Taq DNA polymerase replaced regular Taq. Microsatellite genotypes were obtained using an Applied Biosystems 377 sequencer (Applied Biosystems, Foster City, California, U.S.A.) with a GENESCAN 500Tamra size standard. The genotypes of the individual foxes were obtained using the software programs GENESCAN Version 3.1 and GENOTYPER Version 2.1 (Applied Biosystems). The blood and tissue samples from 20 individuals were reamplified, and the observed error rate per single locus genotype was estimated by calculating the number of errors divided by the number of PCRs. Low quality and concentrations of DNA required repeated analysis of scat samples, and the confidence of the genotypes was estimated using the software package RELIOTYPE (Miller

Table 1. Optimization and polymorphism information, observed heterozygosities, estimates of paternity exclusion probabilities and reagent concentrations for the microsatellite loci used on DNA samples of swift foxes

\begin{tabular}{|c|c|c|c|c|c|c|c|c|}
\hline Locus & Annealing temp $\left({ }^{\circ} \mathrm{C}\right)$ & Number of alleles & Size range & $H(\mathrm{O})$ & $H(\mathrm{E})$ & Exclusion probability & Primer $(\mu \mathrm{M})$ & $\mathrm{MgCl}_{2}(\mathrm{mM})$ \\
\hline $\mathrm{CPH} 3$ & 55 & 6 & $151-161$ & 0.647 & 0.683 & 0.267 & 0.1 & 0.25 \\
\hline CXX403 & 55 & 4 & $273-281$ & 0.305 & 0.305 & 0.048 & 0.2 & 0.25 \\
\hline CXX263 & 51 & 4 & $114-122$ & 0.482 & 0.611 & 0.203 & 0.2 & 0.19 \\
\hline$C \times \times 250$ & 51 & 7 & $132-140$ & 0.440 & 0.631 & 0.222 & 0.3 & 0.38 \\
\hline $\mathrm{FH} 2054$ & 51 & 6 & $175-187$ & 0.627 & 0.650 & 0.231 & 0.2 & 0.25 \\
\hline CXX20 & 55 & 9 & 129-145 & 0.707 & 0.719 & 0.325 & 0.3 & 0.25 \\
\hline CXX173 & 55 & 3 & $124-128$ & 0.317 & 0.298 & 0.044 & 0.2 & 0.25 \\
\hline CXX109 & 55 & 3 & $168-172$ & 0.443 & 0.661 & 0.217 & 0.3 & 0.25 \\
\hline CXX30 & 55 & 11 & $141-157$ & 0.787 & 0.828 & 0.496 & 0.1 & 0.25 \\
\hline CXX2062 & 55 & 6 & 137-154 & 0.651 & 0.683 & 0.269 & 0.1 & 0.38 \\
\hline CXX377 & 55 & 8 & $173-191$ & 0.561 & 0.642 & 0.242 & 0.2 & 0.25 \\
\hline Overall & & 6.09 & & 0.542 & 0.610 & 0.953 & & \\
\hline
\end{tabular}

$H(\mathrm{O})$ and $H(\mathrm{E})$ : observed and expected heterozygosity, respectively. 
et al. 2002). RELIOTYPE is a program for assessing the reliability of an observed multilocus genotype and for directing further replication if the genotype is not sufficiently reliable. Genotypes were replicated until a confidence level of obtaining a correct multilocus genotype of $99 \%$ was reached. We used 44 scat samples in the final analysis.

Relatedness between individuals was assessed using the programs KINSHIP 1.1.2 (Goodnight \& Queller 1999) and CERVUS 2.0 (Marshall et al. 1998). KINSHIP estimates Grafen's (1985) relatedness coefficient between all possible pairs of individuals. This coefficient measures the degree to which two individuals share identical alleles, taking into account the allele frequencies in the population and each individual's genotype (Goodnight \& Queller 1999). Loci with lower than expected heterozygosity levels contribute less to the calculation of $R$ than do loci with higher levels of heterozygosity. $R$ values range between -1 and 1 . A positive $R$ value between two individuals indicates that they are more related (i.e. they share more alleles that are identical by descent) than any two random individuals within the population, and a negative $R$ value indicates that they are less related than any two random individuals within the population. The value of $R$ allows for a determination of the most likely relationship between a pair of individuals. First-degree relatives, either a parent-offspring dyad or full-sibling dyad, should have an $R$ value of approximately 0.5 , half-related individuals (e.g. half-siblings or grandparent-grandchild dyads) should have an $R$ value of approximately 0.25 , and two unrelated individuals should have an $R$ value of approximately 0 . The halfway point between 0.25 and $0.5,0.375$, can be used as a cutoff value to distinguish between fully and half-related individuals (Blouin et al. 1996), but the mean expected heterozygosity was lower than that used by Blouin et al., so we chose an $R$ value of 0.4 to avoid inflated type I error rates. That is, a dyad was not considered a potential parent-offspring dyad unless their $R$ was at least 0.4 .

The program CERVUS was also used to assign parentage. CERVUS uses likelihood ratios to assign parentage to the most likely candidate parent with a predetermined level of confidence (set at 95\%) or leaves parentage unassigned. CERVUS calculates a score (the LOD score) for each candidate parent, based on the genotypes of the candidate parent and offspring. The LOD score is the natural log of the product of the likelihood ratios at each locus, or, equivalently, the sum of the log-likelihood ratios at each locus. The most likely candidate parent is the candidate parent with the highest (most positive) LOD score. Delta is the statistic used to assess the reliability of assigning parentage to the most likely candidate parent. Delta is defined as the difference in LOD scores between the most likely candidate parent and the second most likely candidate parent. Thus, parentage was assumed if the $R$ value for a possible parent-offspring dyad was greater than 0.4 , if the dyad was the most likely candidate according to the LOD score, and no allele mismatches occurred. Deviations from Hardy-Weinberg equilibrium and linkage equilibrium were tested using the program GENEPOP (Raymond \& Rousset 1995) and were corrected for multiple tests using Bonferroni adjustment.

\section{RESULTS}

From January 1997 to December 2000, we obtained an average of 173 radiotelemetry and visual locations on each of 188 swift foxes for a total of 32556 locations. We genotyped 167 foxes. The mean proportion of individuals genotyped at each locus was 0.972 , and 164 individuals were genotyped at a minimum of 10 loci. The error rate of genotyping was estimated at $0.9 \%$. The range of observed heterozygosities per locus was 0.305-0.787 (average $=0.542$ across 11 loci; Table 1 ). The probability of exclusion per locus ranged from 0.048 to 0.496 with an overall probability of exclusion of 0.953 . Significant deviations from Hardy-Weinberg equilibrium were observed at six of the 11 loci when testing the population as a whole. When the Hardy-Weinberg equilibrium was tested within each of the five sampling areas individually, an average of 1.6 loci per area deviated significantly (Table 2). Relatives appear to be clustered within our population (Kitchen 2004), so we attributed the deviations from Hardy-Weinberg equilibrium to the Wahlund effect (Wahlund 1928), which is seen when populations with different allelic frequencies are combined into a single sample. The kin clusters were essentially subpopulations within the population. Further support for this conclusion is that deviations were reduced when we tested each area separately, and we had a low error rate, reducing the possibility that deviations were caused by null alleles. This effect has also been seen in kit fox populations, where similar kin clustering occurs (Ralls et al. 2001). Figure 2 shows the distribution of pairwise relatedness of sampled individuals within the population.

\section{Extrapair Paternity}

We had genetic data for 19 offspring, from at least 15 litters, for which there was one known parent, and a genetic sample from the known mate (based on field data) of that parent, enabling us to test for shared parentage of the offspring by the foxes living in pairs. The sample size of offspring with known parents is relatively small because of the opportunistic nature of trapping efforts, such that few full family groups of parents and offspring were collared and sampled. We also were conservative when classifying offspring to avoid misidentifications; offspring were classified as resulting from extrapair paternity or not only if their parents had been paired for at least 6 months, and parentage by one parent was certain. The precision of the estimate of the prevalence of extrapair paternity is lower with small sample sizes (Griffith et al. 2002). Adults were excluded from parentage if they differed from young at a minimum of two loci. Excluded parents differed from offspring at an mean \pm SD of $3.4 \pm 1.6$ loci.

In 10 cases ( $52 \%$ of young), the mother's social partner was not the father of the offspring, indicating that these offspring had extrapair paternity. These 10 offspring came from at least seven litters; the remaining nine offspring (for which genetic and field data indicate mated parents) came from at least eight litters. The exact number of litters 
Table 2. $P$ values for Hardy-Weinberg proportions test for the population as a whole, and for each area individually

\begin{tabular}{|c|c|c|c|c|c|c|}
\hline \multirow[b]{2}{*}{ Locus } & \multirow[b]{2}{*}{ Whole population } & \multicolumn{5}{|c|}{ Areas } \\
\hline & & BTS & JLA & PRN & RCK & TYR \\
\hline $\mathrm{CPH} 3$ & 0.0022 & 0.1640 & 0.1096 & 0.4121 & 0.3898 & 0.7677 \\
\hline CXX403 & 0.1504 & 0.2215 & 1.0000 & 0.2521 & 0.0747 & 1.0000 \\
\hline$C \times \times 263$ & 0.0000 & 0.0151 & 0.0303 & 0.3690 & 0.2131 & 0.2767 \\
\hline$C X X 250$ & 0.0000 & 0.0004 & 0.0005 & 0.0609 & 0.1687 & 0.0020 \\
\hline $\mathrm{FH} 2054$ & 0.0711 & 0.6695 & 0.0984 & 1.0000 & 0.3500 & 0.8660 \\
\hline CXX20 & 0.3971 & 0.0776 & 0.6395 & 0.8447 & 0.2635 & 0.0982 \\
\hline CXX173 & 0.4144 & 0.4971 & 1.0000 & 0.3883 & 0.4350 & 1.0000 \\
\hline CXX109 & 0.0000 & 0.0376 & 0.0942 & 0.1156 & 0.4859 & 0.0049 \\
\hline CXX30 & 0.0067 & 0.0286 & 0.3019 & 0.3240 & 0.4596 & 0.2699 \\
\hline CXX2062 & 0.1495 & 0.8375 & 0.2077 & 0.3531 & 0.3620 & 0.3450 \\
\hline CXX377 & 0.0037 & 0.0504 & 0.1021 & 0.0438 & 0.4959 & 0.8502 \\
\hline
\end{tabular}

was not known, because some offspring were genetically identified but were collared after leaving the natal den. Two extrapair offspring had the same parents, as did two offspring from socially paired parents.

The extrapair fathers of five offspring were detected by genetic analysis, and in all of these cases, the extrapair fathers were residents in the range immediately neighbouring the range of the mother. Both the extrapair father and the mother in all cases were in a stable pair bond with another fox. One male that was the offspring of an extrapair coupling engaged in successful extrapair mating in a later year. Two males achieved extrapair paternity over consecutive years with the same or different female. We also found that both male and female members of one stable pair engaged in successful extrapair matings with other foxes. Extrapair paternity did not appear to be affected by population density. Only one extrapair offspring was born in the area of highest density, and the other extrapair offspring were born in areas of intermediate densities.

\section{Social Groups}

Fifty-five of 59 swift fox social units (93\%) were malefemale pairs. We had a genetic sample on both individuals for 48 of the 55 pairs $(\bar{X} \pm$ SD $R$ for the male and female in a pair $=-0.014 \pm 0.234)$. Only one pair appeared to be highly related $(R=0.475)$, indicating that swift foxes generally choose unrelated individuals as mates.

There were four trio social groups. Three $(5 \%$ of all social units) of these trios consisted of two males and one female, and the fourth trio consisted of one male and two females (2\%). On average, the relatedness between same-sex members of these groups was high, indicating that these pairs were generally either siblings or parentoffspring $(\bar{X} \pm \mathrm{SD} R=0.458 \pm 0.236$ for the three malemale pairs; $R=0.584$ for the one female-female pair). The relatedness of an individual to an opposite-sex member was low $(R=0.04 \pm 0.334)$, indicating that these trios did not generally consist of a breeding pair and their shared offspring. The trio consisting of two females and a male produced offspring during the study, as did at least one of the trios consisting of two males and one female.

Whether both same-sex members of the trios bred in the same year was unknown, but the following results provide information on the structure and function of the trio groups. (1) In one trio consisting of two males and one female, one male was the most likely father of one offspring, and the other male was the most likely father of another offspring born the following year. (2) In all but one trio (trio $2 ; R=0.469$ between fox 4 and fox 10 ), the

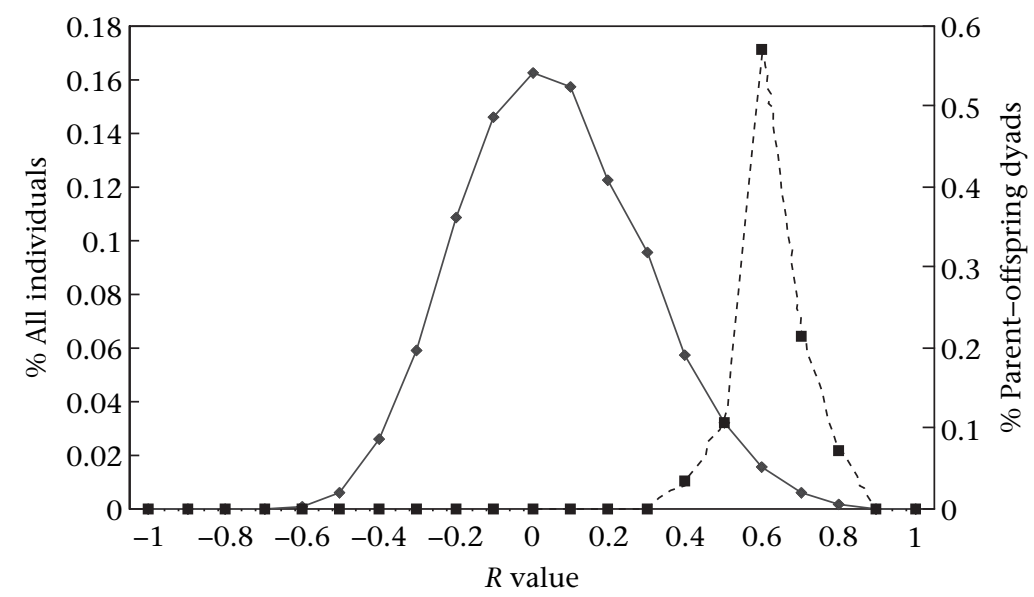

Figure 2. Distribution of pairwise relatedness of all sampled individuals (solid line) and of parent-offspring dyads (dotted line). 
opposite-sex member was unrelated to both of the other trio members. (3) In all but one trio, the trio was stable until the death of one member (i.e. no member left the trio before the trio was disrupted by the death of a trio member). This result suggests that the third individual was not a helper waiting for the optimal time to disperse. In the fourth trio (trio 4), one male of a group consisting of two males and one female left and settled with a single female. However, this male had come from a different natal den, and was not the offspring of either of the other trio members. (4) In all cases except for the male that left his trio before death, the individuals were mature foxes, with one trio consisting of foxes all over an estimated age of 5 years, and a second of foxes all over an estimated age of 4 years.

Each trio had at least one member that was highly related $(R \geq 0.396)$ to a member in at least one other trio (Fig. 3). All four trios were also spatially related (Fig. 4); three social groups had high spatial overlap, but not temporal overlap, of their home ranges. These three trios in turn inherited a home-range area from the previous trio. The other trio held a range separated by only one other range to that of the other trios. All trios held ranges in the area of highest density on the study site (Area BTS, Fig. 1).

\section{Mate Switching}

On three occasions, a swift fox in a stable social group left the group and established a pair bond with another individual, although the first partner remained alive. In all three cases, the new partner was younger than the original mate (by about 1-3 years). In two cases, the fox (one male, one female) that switched mates came from a stable pair bond, and in the third case, a male left a stable trio. The individuals leaving the pair bonds switched to a partner that had been a neighbour before the switch, and the fox leaving the trio travelled approximately $10 \mathrm{~km}$ before settling with a new partner.

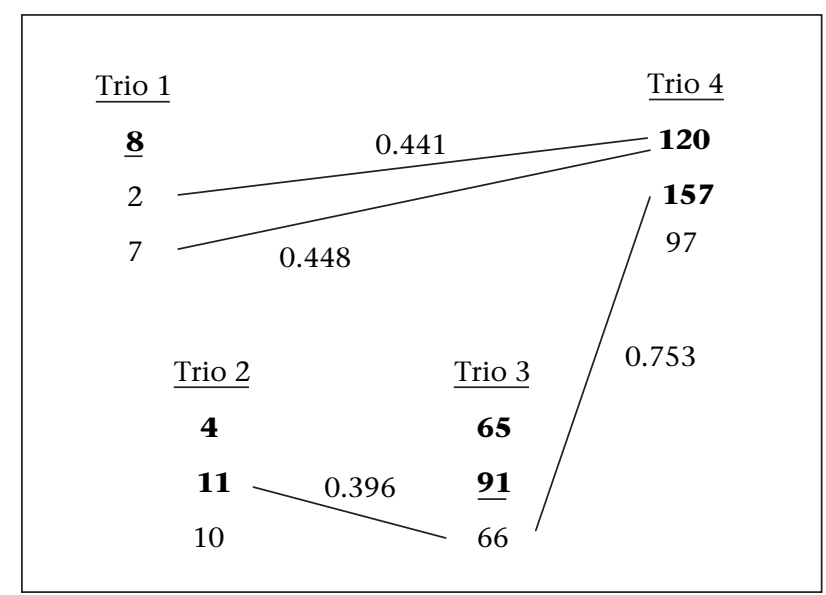

Figure 3. Genetic relatedness observed between members of trio groups of swift foxes ( $R$ values $>0.375$ included). ID numbers for males are shown in bold. Underlined ID numbers refer to foxes that were not genetically identified.

\section{DISCUSSION}

Our results show that swift foxes have a more diverse set of reproductive strategies than previously thought. Foxes often used a mixed mating strategy, with foxes in a stable breeding group engaging in extrapair matings with residents of neighbouring ranges. Thus, social monogamy, which has been documented in swift foxes (via observation and radiotelemetry), does not imply genetic monogamy.

If we had depended upon only the telemetry data, we would have concluded that the fox social units were strictly monogamous, similar to findings from previous studies. Paired foxes occupy a shared home range with a denning area that is exclusive from other social groups (Pechacek et al. 2000; Schauster et al. 2002b; Sovada et al. 2003). They are often located together, particularly during the breeding season (Kitchen 2004), and both participate to some extent in rearing pups (Pruss 1994). There is some evidence that mate guarding during the breeding season may occur (Kitchen et al. 2005). However, there is overlap between neighbouring ranges (Schauster et al. $2002 b)$, allowing for the possibility of extrapair copulations between neighbouring foxes.

Although extrapair paternity has not been previously documented in the swift fox, the occurrence of extrapair paternity is more common than previously thought in many carnivore species and other taxa (e.g. Birkhead \& Møller 1993; Morell 1998; Roemer et al. 2001). Females in some species (e.g. white-nosed coatis, Nasua narica: Gompper 1994; grey seals, Halichoerus grypus: Amos et al. 1993, 1995) mated with alternative males despite being guarded by a single male.

The factors that influence the prevalence of extrapair matings will probably be different for each sex. However, engaging in such behaviour may benefit both sexes, and can thus become relatively common in a population (Reynolds 1996). Trivers (1972) predicted that, because male reproductive success is often predominantly limited by the number of mates fertilized, selection would act to shape a mixed reproductive strategy for males, such as having a stable mate while opportunistically engaging in extrapair matings. Extrapair matings can also benefit females (Reynolds 1996). Some hypotheses of possible benefits to females include fertilization insurance (Levitan \& Peterson 1995), mate assessment (Hunter et al. 1993) and, in some cases, resisting copulation may be more costly (e.g. from increased likelihood of injury) than accepting it (Smuts \& Smuts 1993). In species that require biparental care of offspring, engaging in extrapair copulations may be costly to the female if she risks losing male care of the young. However, this cost is unlikely if the male cannot detect his nonparentage of the offspring. Swift fox males do not seem to be able to detect nonparentage. Males in this study remained in ranges with females and cooperatively raised young that were not their own.

Not only did individual swift foxes use multiple concurrent mating strategies, some foxes in the population also deviated from the norm by forming social groups of three individuals. Although only a small percentage of 

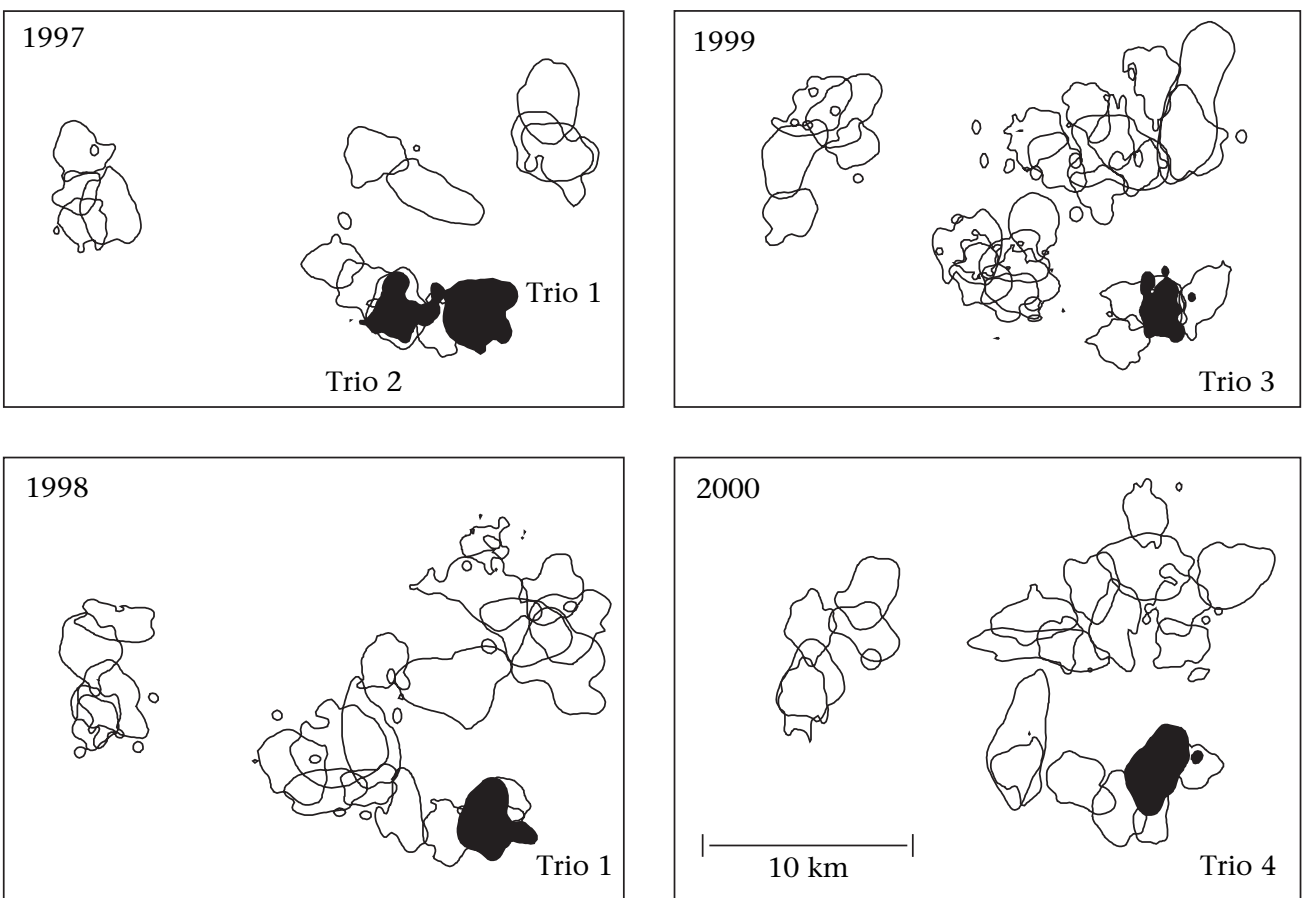

Figure 4. Positions of social groups of trios (bold) and pairs (outline) of swift foxes over 4 years (1997-2000). Single foxes are not shown.

foxes formed trios, trios of both one male and two females and of one female and two males occurred in the population. Groups of three or more animals occur in other generally monogamous canid species. However, typically there is a tendency towards groups of multiple males (e.g. African hunting dogs: van Lawick 1973; Ethiopian wolves: Sillero-Zubiri 1994) or multiple females (e.g. red foxes: Macdonald 1979, bat-eared foxes: Pauw 2000), but not both.

Our results indicate that two factors (population density and inherited behaviours) may have been influential in the formation of trio social groups. Inherited behaviours may have been passed down either genetically, by social learning or a combination of these. All trios in the population occurred in a single area, which had the highest density levels of the five areas. However, there was also a second area with only a slightly lower density where no trio groups were recorded (Schauster et al. 2002a; Fig. 1). Density influences mating systems in canids and other taxa (Voigt \& Macdonald 1984; Richardson \& Burke 2001; Kamler 2002). A higher density may encourage formation of larger groups if all available habitat is held by established social groups. A group of three individuals may also be more effective in defending a territory in a higher-density area than a group of two individuals. Even localized differences in density may affect the behaviour of swift foxes, because numerous foxes in the population chose to settle close to their natal ranges (Kitchen 2004). Foxes would have to weigh the cost of moving a substantial distance to find a range or mate (incurring a risk to do so; transient foxes have a considerably lower survival rate than residents; Schauster et al. 2002b) against the cost of sharing breeding opportunities. Larger groups in higher-density areas may also arise because of factors that influence population density, such as prey abundance (e.g. Sillero-Zubiri 1994). Group size may also be increased if individuals remain in their natal social group because of limited breeding opportunities; a fox in a trio may be making the best of a bad situation instead of an adaptive choice. In fact, mating patterns may be influenced by a number of spatially and temporally changing population and environmental variables, such as population abundance, prey and predator abundance and habitat characteristics.

The four trio groups were also associated genetically and spatially. All groups either inherited territories from one another or were located proximally, and all trios had at least one member that was highly related to a member in at least one other trio. That trios showed levels of high relatedness is not surprising, because of the kin clustering and range inheritance by relatives shown by the foxes (Kitchen 2004). However, this does not discount the possibility that an inherited component may be influential in determining the mating tactics of individual animals.

In addition to the number of mates that an animal copulates with, an individual's choice of a mate has a potential effect on its reproductive output, especially in a species that generally maintains a pair bond with a single mate over much of its breeding life. Engaging in active mate choice, and in mate switching, even after a stable pair bond has been made, has not previously been documented in the swift fox. However, mate switching has been documented in other taxa. For example, the common quail, Coturnix coturnix, engages in mate switching and always chooses a new mate with a higher bodycondition index than the previous mate (Rodrigo-Rueda et al. 1997). The tendency of swift foxes to switch from older to younger partners suggests that foxes may be 
making an active choice designed to maximize their reproductive success. Such behaviour may incur risks however. Duff \& Hunt (1995) found that numerous red fox mortalities during the breeding season were attributable to other red foxes' bite wounds. They concluded that courtship periods might be dangerous because of misinterpretation of behavioural cues between individuals. However, the swift foxes from stable pairs in the current study may have minimized the risk of this behaviour by choosing a new partner that held a neighbouring range. In each case, the 'switcher' was in the area occupied by the new partner before the switch occurred, and thus the fox could determine whether the new partner would accept it before leaving the old one.

In summary, this study shows that several reproductive strategies can exist concurrently in a single swift fox population, demonstrating a high level of individual plasticity in mating tactics. Swift foxes generally maintained stable pair bonds, although they did not always mate for life. Foxes commonly engaged in extrapair matings. We found that swift foxes formed breeding groups of various structures, with the occurrence of trio groups in the population associated with localized variation in population density. Intergroup relatedness in trios was high, indicating that inherited traits encouraging individual variation in these behaviours may be influential.

\section{Acknowledgments}

Funding and logistical support were provided by the Rob and Bessie Welder Wildlife Foundation, Sinton, Texas, the U. S. Army, Directorate of Environmental Compliance and Management, Fort Carson, Colorado, through the U.S. Fish and Wildlife Service, Colorado Fish and Wildlife Assistance Office, Golden, Colorado, and the Utah Cooperative Fish and Wildlife Research Unit at Utah State University. Additional support was provided by the U. S. Department of Agriculture, Wildlife Services, National Wildlife Research Center, Logan Field Station at Utah State University. We thank T. Warren, G. Belew, R. Bunn and B. Rosenlund for support and project coordination. We thank M. Klavetter, E. Bergman, K. Bly, J. Bolis, C. Bromley, R. Cavallaro, L. Gorman, S. Hahn, C. Hamblin, K. Hansen, R. Hare, E. Joyce, S. Kiffe, J. King, S. Langeland, S. Lupis, S. McLellan, J. Milner, M. Pangraze, L. Schafer, L. Schleub, L. Schutte, J. Stamp, H. Tall, J. Weber, W. Weber, M. Wedermyer, B. Wirchansky and T. Young for assistance in the field, P. Terletzky for geographical help, and J. Adams, M. Murphy, C. Miller, C. Anderson and other graduate students and employees at the Laboratory of Ecological and Conservation Genetics at University of Idaho for their help in the laboratory. Katherine Ralls provided optimization specifications of primers used for the kit fox. J. Bissonette, T. Edwards, K. Mock, D. Ramsey and K. Sullivan provided helpful comments on the manuscript. Research protocols were reviewed and approved by Institutional Animal Care and Use Committees at Utah State University and the National Wildlife Research Center.

\section{References}

Alexander, R. D. 1974. The evolution of social behaviour. Annual Review of Ecology and Systematics, 5, 325-383.

Amos, B., Twiss, S., Pomeroy, P. P. \& Anderson, S. S. 1993. Male mating success and paternity in the grey seal, Halichoerus grypus: a study using DNA fingerprinting. Proceedings of the Royal Society of London, Series B, 252, 199-207.

Amos, B., Twiss, S., Pomeroy, P. P. \& Anderson, S. S. 1995. Evidence for mate fidelity in the gray seal. Science, 268, 1897-1899.

Birkhead, T. 1987. Sperm competition in birds. Trends in Ecology and Evolution, 2, 268-272.

Birkhead, T. \& Møller, A. 1993. Female control of paternity. Trends in Ecology and Evolution, 8, 100-103.

Blouin, M. S., Parsons, M., Lacaille, V. \& Lotz, S. 1996. Use of microsatellite loci to classify individuals by relatedness. Molecular Ecology, 5, 393-401.

Covell, D. F. 1992. Ecology of the swift fox (Vulpes velox) in southeastern Colorado. M.S. thesis, University of Wisconsin.

Cypher, B. L. 2003. Foxes. In: Wild Mammals of North America: Biology, Management and Conservation. 2nd edn (Ed. by G. A. Feldhamer, B. C. Thompson \& J. A. Chapman), pp. 511-546. Baltimore, Maryland: Johns Hopkins University Press.

Dietz, J. 1984. Ecology and social organization of the maned wolf (Chrysocyon brachyurus). Smithsonian Contributions to Zoology, 392, 1-51.

Duff, J. P. \& Hunt, B. 1995. Courtship and mortality in foxes (Vulpes vulpes). Veterinary Record, 136, 367.

Egoscue, H. G. 1979. Vulpes velox. Mammalian Species, 122, 1-5.

Frafjord, K. 1993. Reproductive effort in the Arctic fox, Alopex lagopus: a review. Norwegian Journal of Agricultural Sciences, 7, 301-309.

Francisco, L. V., Langston, A. A., Mellersh, C. S., Neal, C. L. \& Ostrander, E. A. 1996. A class of highly polymorphic tetranucleotide repeats for canine genetic mapping. Mammalian Genome, 7, 359-362.

Fredholm, M. \& Wintero, A. K. 1995. Variation of short tandem repeats within and between species belonging to the Canidae family. Mammalian Genome, 6, 11-18.

Geffen, E. \& Macdonald, D. W. 1992. Small size and monogamy: spatial organization of Blanford's foxes, Vulpes cana. Animal Behaviour, 44, 1123-1130.

Geffen, E., Gompper, M. E., Gittleman, J. L., Luh, H., Macdonald, D. W. \& Wayne, R. 1996. Size, life-history traits, and social organization in the Canidae: a reevaluation. American Naturalist, 147, 140-160.

Gese, E. M., Rongstad, O. J. \& Mytton, W. R. 1988. Home-range and habitat use of coyotes in southeastern Colorado. Journal of Wildlife Management, 52, 640-646.

Gompper, M. E. 1994. The importance of ecology, behavior, and genetics in the maintenance of coati (Nasua narica) social structure. Ph.D. thesis, University of Tennessee, Knoxville.

Goodnight, R. T. \& Queller, D. C. 1999. Computer software for performing likelihood tests of pedigree relationship using genetic markers. Molecular Ecology, 8, 1231-1234.

Goossens, B., Graziani, L., Waits, L. P., Farrand, E., Magnolon, S., Coulon, J., Bel, M., Taberlat, P. \& Allainé, D. 1998. Extra-pair paternity in the monogamous Alpine marmot revealed by nuclear DNA microsatellite analysis. Behavioral Ecology and Sociobiology, 43, 281-288.

Grafen, A. 1985. A geometric view of relatedness. Oxford Surveys in Evolutionary Biology, 2, 28-29.

Griffith, S. C., Owens, I. P. F. \& Thuman, K. A. 2002. Extra pair paternity in birds: a review of interspecific variation and adaptive function. Molecular Ecology, 11, 2195-2212. 
Hughes, C. 1998. Integrating molecular techniques with field methods in studies of social behaviour: a revolution of results. Ecology, 79, 383-399.

Hunter, F. M., Petrie, M., Otronen, M., Birkhead, T. \& Møller, A. P. 1993. Why do females copulate repeatedly with one male? Trends in Ecology and Evolution, 8, 21-26.

Kamler, J. 2002. Relationships of swift foxes and coyotes in northwest Texas. Ph.D. thesis, Texas Tech University.

Kilgore, D. L. 1969. An ecological study of the swift fox (Vulpes velox) in the Oklahoma Panhandle. American Midland Naturalist, 81, 512-534.

Kitchen, A. M. 2004. Social and spatial ecology of the swift fox (Vulpes velox) in southeastern Colorado. Ph.D. thesis, Utah State University.

Kitchen, A. M., Gese, E. M. \& Schauster, E. R. 1999. Resource partitioning between coyotes and swift foxes: space, time, and diet. Canadian Journal of Zoology, 77, 1645-1656.

Kitchen, A. M., Gese, E. M., Karki, S. \& Schauster, E. R. 2005. Spatial ecology of swift fox groups: from group formation to mate loss. Journal of Mammalogy, 86, 547-554.

Kleiman, D. G. 1977. Monogamy in mammals. Quarterly Review of Biology, 52, 39-69.

van Lawick, H. 1973. Solo. London: Collins.

Levitan, D. R. \& Peterson, C. 1995. Sperm limitation in the sea. Trends in Ecology and Evolution, 10, 228-231.

Linhart, S. B. \& Knowlton, F. F. 1967. Determining age of coyotes by tooth cementum layers. Journal of Wildlife Management, 31, 362-365.

Longmire, J. L., Ambrose, R. E., Brown, N. C., Cade, T. J., Maechtle, T., Seegar, W. S., Ward, F. P. \& White, C. M. 1991. Use of sex-linked minisatellite fragments to investigate genetic differentiation and migration of North American populations of the peregrine falcon (Falco peregrinus). In: DNA Fingerprinting: Approaches and Applications (Ed. by T. Burke, G. Dolf, A. Jeffreys \& R. Wolff), pp. 217-229. Brasil, Switzerland: Birkhäuser Press.

Macdonald, D. W. 1979. 'Helpers' in fox society. Nature, 282, 69-71.

Macdonald, D. W. 1983. The ecology of carnivore social behaviour. Nature, 301, 379-384.

McRae, S. B. \& Kovacs, K. M. 1994. Paternity exclusion by DNA fingerprinting and mate guarding in the hooded seal Cystophora cristata. Molecular Ecology, 3, 101-107.

Marshall, T. C., Slate, J., Kruuk, L. E. B. \& Pemberton, J. M. 1998. Statistical confidence for likelihood-based paternity inference in natural populations. Molecular Ecology, 7, 639-655.

Mech, L. D. 1983. Handbook of Animal Radiotracking. Minneapolis: University of Minnesota Press.

Miller, C., Joyce, P. \& Waits, L. 2002. Assessing allelic dropout and genotype reliability using maximum likelihood. Genetics, 160, 357-366.

Moehlman, P. D. 1986. Ecology of cooperation in canids. In: Ecological Aspects of Social Evolution (Ed. by D. Rubenstein \& R. Wrangham), pp. 64-86. Princeton, New Jersey: Princeton University Press.

Morell, V. 1998. A new look at monogamy. Science, 281, 1982-1983.

Ostrander, E. A., Sprague, G. F. \& Rine, J. 1993. Identification and characterization of dinucleotide repeat (CA)n markers for genetic mapping in dog. Genomics, 19, 207-213.

Pauw, A. 2000. Parental care in a polygynous group of bat-eared foxes, Otocyon megalotis (Carnivora: Canidae). African Zoology, 35, 139-145.

Pechacek, P., Lindzey, F. G. \& Anderson, S. H. 2000. Home range size and spatial organization of swift fox Vulpes velox (Say, 1823) in southeastern Wyoming. Zeitschrift für Saügetierkunde, 65, 209-215.
Pruss, S. D. 1994. An observational natal den study of wild swift fox (Vulpes velox) on the Canadian Prairie. M.Sc. thesis, University of Calgary.

Ralls, K., Pilgrim, K. L., White, P. J., Paxinos, E. E., Schwartz, M. K. \& Fleischer, R. C. 2001. Kinship, social relationships, and den sharing in kit foxes. Journal of Mammalogy, 82, 858-866.

Raymond, M. \& Rousset, F. 1995. GENEPOP version 1.2: population genetic software for exact tests and ecumenicism. Journal of Heredity, 86, 248-249.

Reynolds, J. D. 1996. Animal breeding systems. Trends in Ecology and Evolution, 11, 68-72.

Richardson, D. S. \& Burke, T. 2001. Extrapair paternity and variance in reproductive success related to breeding density in Bullock's orioles. Animal Behaviour, 62, 519-525.

Rodrigo-Rueda, F. J., Rodriguez-Teijeiro, J. D., Puigcerver, M. \& Gallego, S. 1997. Mate switching in a non-monogamous species? The case of the common quail (Coturnix coturnix). Ethology, 103, 355-364.

Roemer, G. W., Smith, D. A., Garcelon, D. K. \& Wayne, R. K. 2001. The behavioural ecology of the island fox (Urocyon littoralis). Journal of Zoology, 255, 1-14.

Saiki, R. K., Scharf, S. \& Faloona, F. 1985. Enzymatic amplification of b-globin genomic sequences and restriction site analysis for diagnosis of sickle cell anemia. Science, 230, 1350-1354.

Schauster, E. R., Gese, E. M. \& Kitchen, A. M. 2002a. An evaluation of survey methods for monitoring swift fox abundance. Wildlife Society Bulletin, 30, 464-477.

Schauster, E. R., Gese, E. M. \& Kitchen, A. M. 2002b. Population ecology of swift foxes (Vulpes velox) in southeastern Colorado. Canadian Journal of Zoology, 80, 307-319.

Shaw, R. B., Anderson, S. L., Schulz, K. A. \& Diersing, V. E. 1989. Plant communities, ecological checklist, and species list for the U.S. Army Piñon Canyon Maneuver Site, Colorado. Colorado State University. Science Series, 37, 1-84.

Sheldon, J. 1992. Wild Dogs: the Natural History of the Nondomestic Canidae. San Diego: Academic Press.

Sillero-Zubiri, C. 1994. The behavioural ecology of the Ethiopian wolf, Canis simensis. Ph.D. thesis, Oxford University.

Smuts, B. B. \& Smuts, R. W. 1993. Male aggression and sexual coercion of females in nonhuman primates and other mammals: evidence and theoretical implications. Advances in the Study of Behaviour, 22, 1-63.

Sovada, M. A., Slivinski, C. C. \& Woodward, R. O. 2003. Home range, habitat use, pup dispersal and litter sizes of swift foxes in western Kansas. In: Ecology and Conservation of Swift Foxes in a Changing World (Ed. by M. Sovada \& L. Carbyn), pp. 149160. Saskatchewan: University of Regina Press.

Trivers, R. L. 1972. Parental investment and sexual selection. In: Sexual Selection and the Descent of Man (Ed. by B. Campbell), pp. 136-179. Chicago: Aldine Press.

Vardenplas, S., Wild, I., Grober-Rabie, A., Brebrer, K., Ricketts, M., Wallis, A., Bester, A., Boyd, C. \& Mathew, C. 1984. Blot hybridization analysis of genomic DNA. Journal of Medical Genetics, 21, 164-168.

Voigt, D. R. \& Macdonald, D. W. 1984. Variation in the spatial and social behaviour of the red fox, Vulpes vulpes. Acta Zoologica Fennica, 171, 261-265.

Wahlund, S. 1928. Zusammensetzung von population und korrelationerscheinungen von standpunkt der vererbungslehre ans betrachtet. Hereditas, 11, 65-106.

Westneat, D. F. 1987a. Extra-pair fertilizations in a predominantly monogamous bird: genetic evidence. Animal Behaviour, 35, 877886. 
Westneat, D. F. 1987b. Extra-pair fertilizations in a predominantly monogamous bird: observations of behaviour. Animal Behaviour, 35, 877-886.

Westneat, D. F., Sherman, P. W. \& Morton, M. L. 1990. The ecology and evolution of extra-pair copulations in birds. In: Current Ornithology. Vol. 7 (Ed. by D. M. Powers), pp. 331-369. New York: Plenum.
White, G. C. \& Garrott, R. A. 1990. Analysis of Radio-tracking Data. New York: Academic Press.

Worton, B. J. 1989. Kernel methods for estimating the utilization distribution in home range studies. Ecology, 70, 164-168.

Zumbaugh, D. M., Choate, J. R. \& Fox, L. B. 1985. Winter food habits of the swift fox on the central high plains. Prairie Naturalist, $17,41-47$. 